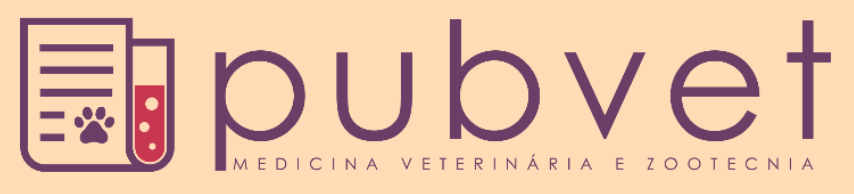

https://doi.org/10.31533/pubvet.v12n11a211.1-6

\title{
Correlação entre variáveis produtivas e eficiência de resposta a suplementação em vacas Guzerá em lactação
}

\author{
Arthur Alves Silva*1ఠ, Breno Mourão de Sousa ${ }^{2}$, Ricardo Reis e Silva ${ }^{3}$, Ana Luiza \\ Costa Cruz Borges ${ }^{4}{ }^{\ominus}$, Isabela Carvalho Costa $^{50}$, Frederico Guimarães Barata ${ }^{6} \theta$, \\ Pedro Henrique de Araújo Carvalho ${ }^{7}$, Ana Luiza Moreira Silva ${ }^{8} \bullet$
}

\begin{abstract}
${ }^{I}$ Doutorando da Universidade Federal de Minas Gerais, Departamento de Zootecnia. Belo Horizonte, Minas Gerais, Brasil. ${ }^{2}$ Professor do Centro Universitário UniBH, Medicina Veterinária, Belo Horizonte, Minas Gerais, Brasil.

${ }^{3}$ Professor da Universidade Federal de Minas Gerais, Departamento de Zootecnia. Belo Horizonte, Minas Gerais, Brasil. ${ }^{4}$ Professor da Universidade Federal de Minas Gerais, Departamento de Zootecnia. Belo Horizonte, Minas Gerais, Brasil. ${ }^{5}$ Mestranda da Universidade Federal de Minas Gerais, Departamento de Zootecnia. Belo Horizonte, Minas Gerais, Brasil. ${ }^{6}$ Mestrando da Universidade Federal de Minas Gerais, Departamento de Zootecnia. Belo Horizonte, Minas Gerais, Brasil. ${ }^{7}$ Doutorando da Universidade Federal de Minas Gerais, Departamento de Zootecnia. Belo Horizonte, Minas Gerais, Brasil. ${ }^{8}$ Estudante de Medicina Veterinária da Universidade Federal de Minas Gerais. Belo Horizonte, Minas Gerais, Brasil.

*Autor para correspondência, E-mail: arthur.zootecnia@gmail.com
\end{abstract}

\begin{abstract}
RESUMO. As pesquisas em nutrição especializada para zebuínos no Brasil são pouco avançadas e difundidas, logo especializar e aprofundar o conhecimento cientifico sobre a fisiologia e características produtivas deste grupo são de grande valia para os criatórios, uma vez que a pecuária está se tornando cada vez mais competitiva e o lucro do produtor está altamente relacionada com a produtividade de cada animal. Desta forma o presente trabalho avaliou de forma inédita e descreveu a eficiência de resposta a suplementação em vacas Guzerá, definindo os níveis ideias de arraçoamento para as diversas produções de leite. Foram utilizadas 109 vacas puras de origem entre primíparas e multíparas, que foram arraçoadas em média com 3,42 kg/dia e com produção leiteira média de 10,4 kg/dia. Vacas guzerá apresentam $\mathrm{MR}=2,32$ e está tem alta correlação com dias em lactação, ordem de parição e produção leiteira.
\end{abstract}

Palavras chave: eficiência, guzerá, leite, nutrição, ruminantes

\section{Variable correlation between production and efficiency in response to supplement in lactating cows Guzerat}

ABSTRACT. Research in specialized nutrition for zebu cattle in Brazil are somewhat advanced and widespread, specialize and deepen the scientific knowledge about the physiology and production characteristics of this group are of great value to breeders, since the livestock industry is becoming increasingly competitive and the producer's profit is highly correlated with the productivity of each animal. Thus, the present study evaluated in an unprecedented manner and described the efficiency of response to supplementation in cows Guzerat, defining ideas feeding levels for different milk production. 109 cows pure source between primiparous and multiparous supplemented which were on average 3.42 $\mathrm{kg} / \mathrm{day}$ and the average milk production $10,42 \mathrm{~kg} / \mathrm{day}$ were used. Guzerat cows have $\mathrm{MR}=$ 2.32 , and it is highly correlated with days in milk, lactation numbers and milk production.

Keywords: efficiency, guzerat, milk, nutrition, ruminants 


\title{
La correlación entre variables productivas y eficiencia de respuesta a la suplementación en vacas Guzerá en lactancia
}

\begin{abstract}
RESUMEN. Las investigaciones en nutrición especializada para cebúos en Brasil son poco avanzadas y difundidas, luego especializar y profundizar el conocimiento científico sobre la fisiología y características productivas de este grupo son de gran valor para los creatorios, una vez que la ganadería se está volviendo cada vez más competitiva y el beneficio del productor está altamente relacionado con la productividad de cada animal. De esta forma el presente trabajo evaluó de forma inédita y describió la eficiencia de respuesta a la suplementación en vacas Guzerá, definiendo los niveles ideas de arraciamiento para las diversas producciones de leche. Se utilizaron 109 vacas puras de origen entre primíparas y multíparas, que fueron arraciadas en promedio con 3,42 kg / día y con producción lechera media de 10,42 kg / día. Las vacas Guzerá presentan $\mathrm{MR}=2,32$, y está alta correlación con días en lactación, orden de parición y producción lechera.
\end{abstract}

Palabras clave: eficiencia, Guzerá, leche, nutrición, rumiantes

\section{Introdução}

As últimas décadas da pecuária leiteira nacional vêm mostrando profundas mudanças de paradigmas. Os tradicionais sistemas extensivos de produção de leite estão sendo gradativamente substituídos por sistemas melhor geridos e mais técnicos, visando a melhor remuneração do empresário rural (Santos et al., 2010). Desta forma, minimizar custos e aumentar a lucratividade na atividade passaram a ser objetivos mínimos para este novo tipo de produtor. Aumentar a lucratividade significa aumentar a eficiência produtiva dos animais criados em propriedades leiteiras. Neste contexto, a produção intensiva de leite em pasto está sendo reconhecida não mais como sistema alternativo para produção de leite, mas como solução para propriedades leiteiras (Fukumoto et al., 2010; Magalhães et al., 2007; Silva et al., 2012).

Naturalmente a forrageira tropical possui alto teor de fibra e, quando mal manejada, proporciona baixos valores nutricionais, fazendo com que o animal consuma menos e, consequentemente, produza menos (Moreira et al., 2004). Dessa forma a procura por um consumo do animal que otimize a eficiência alimentar, tendo como alternativa a suplementação concentrada é de grande valia para a produção sustentável (Porto et al., 2009).

A suplementação concentrada na produção de leite a pasto é uma alternativa para o aumento na produtividade animal. Entretanto, deve sempre estar atento e monitorar o custo dessa suplementação, procurando saber até que ponto deve utiliza-lo para atingir o objetivo (Porto et al., 2009). Desta forma, para reduzir os custos com alimentação, é necessário buscar e obter eficiência na utilização dos alimentos (Castillot et al., 2000). $\mathrm{O}$ conceito da eficiência alimentar foi tão bem aceito por pesquisadores e pela indústria mundial que deverá ser aplicado como marcador para minimizar os custos com alimentação, bem como aumentar a lucratividade do setor leiteiro (Castillot et al., 2000).

Este trabalho foi realizado para avaliar a eficiência de resposta a suplementação em vacas lactantes da raça Guzerá nos parâmetros produtivos e econômicos.

\section{Material e métodos}

$\mathrm{O}$ experimento foi conduzido em três fazendas no estado de Minas Gerais, nos municípios de Uberaba e Curvelo. Foram utilizadas cento e nove vacas, sendo 39 primíparas, 52 vacas de segunda cria, 14 vacas de terceira cria e 4 vacas de quarta cria da raça Guzerá, com produção média diária de $10,4 \mathrm{~kg}$ de leite/dia. Os dias em lactação médio das cento e nove vacas foram de 117 dias. Todas as vacas estavam com o escore de condição corporal entre 2,0 a 3,5. As vacas foram ordenhadas mecanicamente duas vezes ao dia, nos seguintes horários: das 6:00 as 9:30 e das 14:00 as 17:30, e com intervalo médio ordenha de sete horas. A coleta dos dados ocorreu entre os dias 28/07/2014 a 11/09/2014. O leite foi mensurado por um medidor de leite em fluxo de cada ordenha mecânica.

As vacas se encontravam em um regime alimentar recebendo como alimento volumoso silagem de sorgo (Sorghum bicolor) ou silagem de sorgo e feno de tifton (Cynodon dactylon).O concentrado foi ofertado de acordo com a produção individual leiteira de cada vaca, que variava de três a cinco quilos por dia, com média 
de $3,42 \mathrm{~kg} / \mathrm{dia}$, em uma das fazendas utilizava-se resíduo de cervejaria como suplemento fibroso, a agua se encontrava nas propriedade a vontade para consumo. A análise bromatológica destes alimentos seguiram as metodologias de $\underline{\mathrm{AOAC}}$ (2005) para matéria seca, proteína bruta, extrato etéreo, matéria mineral. A metodologia descrita por Van Soest et al. (1991) foi usada para determinação da fibra em detergente neutro e fibra em detergente ácido. Os carboidratos não fibrosos foram analisados de acordo com a metodologia proposta por Sniffen et al. (1992).

A análise estatística foi processada no software SAS $^{\circledR}$ (Statistical Analysis System), pela análise de correlação simples entre as variáveis medidas, com criação de dados médios de MR com dias em lactação e com a ordem de parição.

\section{Resultado e discussão}

As vacas lactantes que compuseram o experimento apresentaram média de produção de $10,4 \mathrm{~kg} /$ dia com consumo médio de ração de 3,3 kg/dia, com ordem e dias em lactação médio de 1,84 e 117 dias, respectivamente.

As composições bromatológicas dos alimentos presentes nas dietas das 109 vacas se encontram na tabela 1.

A eficiência de resposta a suplementação (MR) é calculada pela divisão do kg de leite produzido pelo kg de suplemento concentrado oferecido. É a eficiência que a vaca terá ao tratamento com concentrado, ou seja, quanto de leite irá produzir para cada $\mathrm{kg}$ de concentrado consumido (Souza, $\underline{2006)}$.

A eficiência de resposta a suplementação foi mensurada por um gráfico de dispersão entre produção leiteira diária (eixo Y) e concentrado ofertado (eixo X), desta forma podemos observar que a cada $1 \mathrm{~kg}$ de concentrado ofertado há um aumento de produção de $2,3 \mathrm{~kg}$ de leite, sendo o coeficiente de determinação desta equação de 0,2042 .

Existem diversos fatores intrínsecos e extrínsecos ao animal que afetam a MR:

Tabela 1. Composição bromatológica dos alimentos, \% da matéria seca

\begin{tabular}{lcccc}
\hline & Ração 1 & Ração 2 & Silagem de sorgo & Feno de tifton \\
\hline Matéria seca & 87,91 & 91,70 & 28,08 & 91,60 \\
Proteína bruta & 9,05 & 39,10 & 6,26 & 9,12 \\
Extrato etéreo & 4,02 & 20,97 & 3,39 & 1,75 \\
Matéria mineral & 1,61 & 4,96 & 5,10 & 7,18 \\
Fibra em detergente neutro & 13,91 & 20,77 & 53,33 & 77,68 \\
Fibra em detergente ácido & 4,00 & 13,34 & 32,53 & 39,82 \\
Carboidratos não fibrosos & 71,55 & 12,40 & 29,52 & 6,57 \\
\hline
\end{tabular}

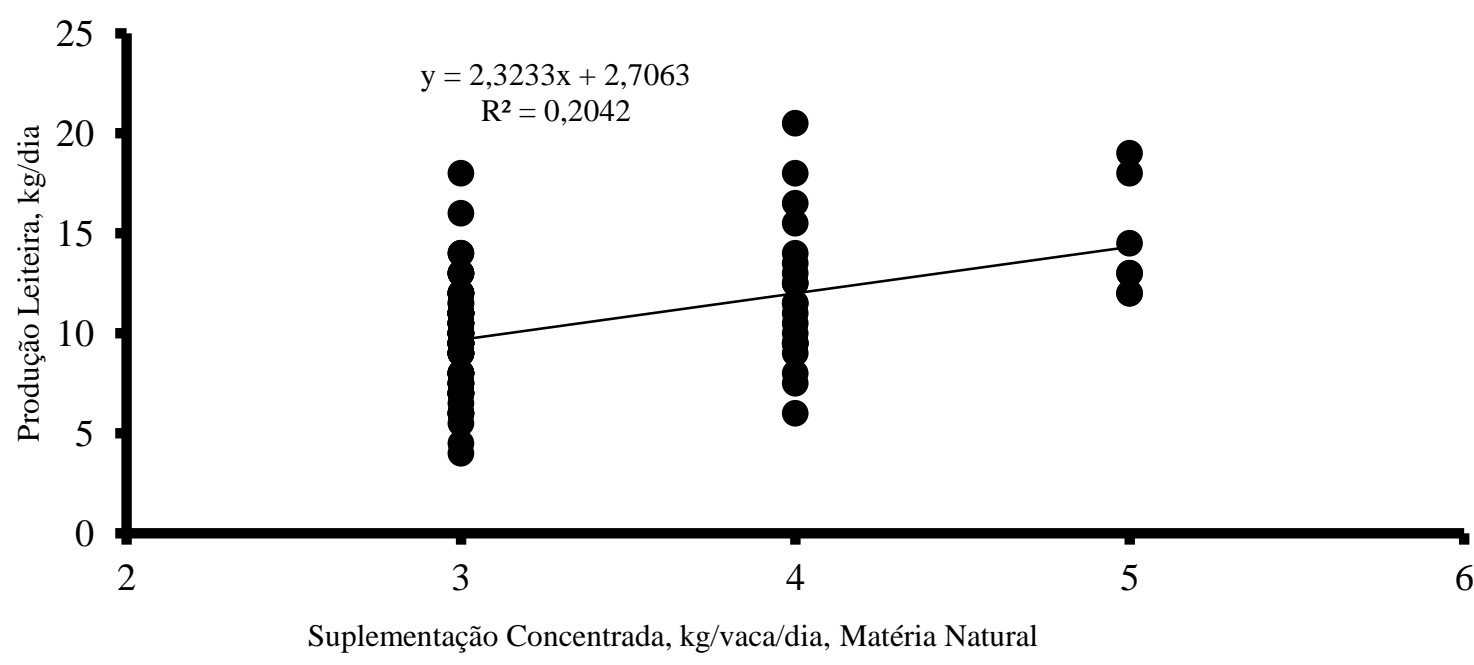

Gráfico 1. Análise de regressão da eficiência de resposta a suplementação $(\mathrm{kg} / \mathrm{kg})$ em vacas Guzerá em lactação 
Produção leiteira: Vacas de alta produção apresentam maior MR comparadas com animais de baixa produção, isto se deve a capacidade destes animais serem energeticamente mais eficientes, ou seja, apresentam proporcionalmente uma maior conversão de energia consumida em produção leiteira, tendo um gasto energético com a mantença inferior aos animais de baixa produção (Castillot et al., 2000).

Leão et al. (2013) analisaram tendências genéticas da produção de leite em rebanhos da raça Guzerá com aptidão leiteira, sendo avaliadas produções das progênies de touros do Programa Nacional de Melhoramento do Guzerá para leite, em tal pesquisa foi possível inferir uma tendência genética positiva para a produção de leite na ordem de $8,4 \mathrm{~kg} / \mathrm{ano}$. Entretanto, os autores concluíram que não basta somente melhorar o valor genético dos animais é necessário aprimorar as condições ambientais para que o animal manifeste seu desempenho máximo.

Santos et al. (2010) analisaram dados da literatura brasileira que corroboram com as afirmativas de Leão et al. (2013) que quanto maior for a produção leiteira, maior a MR. Observou-se nos referidos dados que a produção leiteira responde por $73 \%$ das fontes de variação da MR em vacas leiteiras.

Ordem de parição: Vacas de primeira lactação apresentam valores menores de MR, pelo fato de desviarem os nutrientes que iriam para a glândula mamaria para o termino do seu crescimento. Vacas adultas tem em média valores de MR de 0,1 a 0,2 unidades maiores que as primíparas(Hutjens, 2006). Rangel et al. (2009) ponderaram em suas analises que a ordem de parto teve influência significativa sobre a produção leiteira de vacas Guzerá. Vacas de quinta ordem de parição apresentam as melhores médias produtivas de leite e duração do período de lactação.

Dias em lactação: Segundo Castillot et al. (2000) analisando dados de rebanhos da raça Holandês, a MR diminui com o passar dos dias em lactação, onde vacas no terço inicial da lactação apresentam elevado MR. Contudo no terço médio e final ela decai, segundo os autores no início da lactação a MR elevada (superior a 1,8), pode indicar uma quantidade significativa de escore corporal que está sendo mobilizado para apoiar a produção de leite. Entretanto, se as reservas corporais não forem controladas estas poderão se esgotar e afetar negativamente a produção leiteira, o outro extremo MR muito baixo no início da lactação (inferior a 1,2), pode sinalizar problemas de saúde, o valor médio neste tipo de rebanho varia de 1,5 a 1,6 para vacas de 150 a 200 dias de lactação, para vacas acima de 250 dias de lactação espera-se valores inferiores a 1,4.

A seleção para a produção de leite total na lactação causa acréscimo na produção inicial e mudanças inexpressivas na taxa de declínio da produção de leite, não alterando, assim, o formato da curva de lactação. Vacas da raça Guzerá com maiores produções iniciais apresentam declínios na produção de leite mais acentuados ao longo da lactação (Cobuci et al., 2011).

Qualidade e digestibilidade da forragem: Segundo estudos compilados por Santos et al. (2010) a qualidade e digestibilidade da foragem são um dos fatores mais crítico para se obter MR superiores a 1,4 dentre os alimentos que compõe a dieta. Para aumentar a produção de leite ou a MR, não basta aumentar o consumo de matéria seca, e sim o de matéria seca digestível. Logo, altas produções de leite podem ser alcançadas com o aumento no consumo de matéria seca digestível, que é acompanhada do aumento da energia disponível para o animal (energia liquida que é responsável pela produção). Diferente de grãos e outros suplementos concentrados, volumosos têm valores de digestibilidade bastante variados, exercendo impacto direto nos valores finais da MR. Portanto, submeter o alimento volumoso a análises bromatológicas é um passo importante para melhorias dos valores de MR de rebanhos leiteiros.

Composição do leite: A composição do leite faz parte das novas metas do pecuarista brasileiro, a fim de garantir um produto de qualidade para o consumo humano e maior remuneração por litro de leite (Santos et al., 2008). Trabalhos nacionais compilados por Santos et al. (2010) não foi observado efeito significativo do nível de suplementação sobre o teor de gordura do leite, mostrando a baixa dependência do teor de gordura do leite com a quantidade de suplemento. Isso pode ser explicado pela capacidade teórica das pastagens de clima tropical serem excelentes fontes de precursores para a gordura do leite (Santos et al., 2008). Bargo et al. (2003) mencionaram que a concentração proteica do leite aumenta com a suplementação. Os autores comentaram sobre o efeito da natureza dos suplementos concentrados sobre a concentração de proteína no leite, essa concentração reduziu quando concentrados ricos em amido foram substituídos por aqueles ricos em fibra. 
Quanto a correlação entre as variáveis analisadas apresentara as seguintes relações: a produção diária teve correlação positiva com ordem de parição de 62,6\% $(<0,001)$, ou seja, a cada lactação a mais a produção leiteira aumenta em $62,63 \%$. A correlação da produção diária com dias em lactação foi negativa em 73,9\% $(<0,001)$, ou seja, a produção diária de vacas Guzerá sofre um decréscimo com o terço do período de lactação em $-73,9 \%$. Como observamos na tabela 2.

Tabela 2. Correlação entre a produção de leite, a ordem de parição e dias em lactação de vacas Guzerá em lactação

\begin{tabular}{lccc}
\hline & $\begin{array}{c}\text { Produção } \\
\text { diária de leite }\end{array}$ & Ordem & $\begin{array}{c}\text { Dias em } \\
\text { lactação }\end{array}$ \\
\hline $\begin{array}{l}\text { Produção } \\
\text { diária de leite }\end{array}$ & $\mathbf{1 , 0 0 0 0}$ & & \\
Ordem & 0,6263 & $\mathbf{1 , 0 0 0 0}$ & \\
Dias em & $<.0,0001$ & & \\
lactação & $-0,7386$ & $-0,3397$ & $\mathbf{1 , 0 0 0 0}$ \\
\hline
\end{tabular}

A produção leiteira de vacas Guzerá correlacionando com a ordem de parição teve diferença estatística em 3 grupos testados, vacas primíparas tem sua produção estatisticamente igual a vacas de segunda cria, porem inferiores à de vacas de terceira e quarta cria, vacas de segunda lactação teve sua produção leiteira estatisticamente semelhante a vacas de primeira e terceira cria. Vacas de terceira cria tem sua produção menor de vacas de quarta lactação, porém similar de vacas de segunda ordem, como observamos na tabela 3 . Isso demonstra que vacas Guzerá continuam tendo um acréscimo na produção após a terceira lactação.

Tabela 3. Produção leiteira de vacas Guzerá correlacionando com a ordem de parição

\begin{tabular}{lcc}
\hline \multicolumn{2}{l}{ Ordem de parição Produção média diária de } & n \\
leite & \\
\hline 4 & $17,375 \mathrm{a}$ & 4 \\
3 & $12,250 \mathrm{~b}$ & 14 \\
2 & $10,933 \mathrm{~b} \mathrm{c}$ & 52 \\
1 & $8,372 \mathrm{c}$ & 39
\end{tabular}

Letras diferentes entre colunas diferentes estatisticamente pelo teste de Tukey $(n=109)$

\section{Conclusão}

O zebu leiteiro no Brasil apesar de ser muito difundido e adaptado as condições ambientais, ainda apresentam poucas pesquisas cientificas acadêmicas, desta forma aumentar o conhecimento técnico sobre esse grupo é de extrema importância, pois diminuirá os erros de manejo e aumentará o lucro ao produtor. Desta forma, o presente trabalho avaliou de forma a eficiência de resposta a suplementação em vacas guzerá e obteve como resultado uma MR de 2,32, ou seja a cada $1 \mathrm{~kg}$ de concentrado oferecido obteve um acréscimo na produção de $2,32 \mathrm{~kg}$ de leite. A pesquisa também ponderou que existem fatores que interferem nesta eficiência e que são extremamente importantes, como ordem de parição, dias em lactação e produção leiteira total.

\section{Referências}

AOAC. 2005. - Association Official Analytical Chemist 2005 (Official Methods of Analysis (18th ed.) ed.. Gaitherburg, Maryland, USA: AOAC.

Bargo, F., Muller, L. D., Kolver, E. S., \& Delahoy, J. E. 2003. Invited review: Production and digestion of supplemented dairy cows on pasture. Journal of Dairy Science, 86(1), 1-42.

Castillot, A. R., Kebreab, E., Beever, D. E., \& France, J. 2000. A review of efficiency of nitrogen utilisation in lactating dairy cows and its relationship with. Journal of Animal and Feed Sciences, 9(1), 1-32.

Cobuci, J. A., Costa, C. N., Braccini Neto, J., \& Freitas, A. F. 2011. Genetic parameters for milk production by using random regression models with different alternatives of fixed regression modeling. Revista Brasileira de Zootecnia, 40(3), 557-567.

Fukumoto, N. M., Damasceno, J. C., Deresz, F., Martins, C. E., Cóser, A. C., \& Santos, G. T. 2010. Milk yield and composition, feed intake and stocking rate of crossbread cows in tropical grasses managed in a rotational grazing system. Revista Brasileira de Zootecnia, 39(7), 1548-1557.

Hutjens, M. F. 2006. Dairy feeding efficiency. Paper presented at the Southeast dairy herd management conference proceeding.

Leão, G. F. M., Pivatto, D. R. D., Carniel, H., Rodrigues, M. G. K., Braga, R. A., Silva, M. R. H., \& Teixeira, P. P. M. 2013. Melhoramento genético em zebuínos leiteiros: uma revisão. Agropecuária Científica no Semiárido, 9(4), 914.

Magalhães, J., Carneiro, M., Bezerra, A., Morais Neto, L., Costa, M., \& Mochel Filho, W. 2007. Considerações sobre a produção de leite a pasto. Revista Electrónica de Veterinária, 8(9), 12-21. 
Moreira, F. B., Prado, I. N., Cecato, U., Wada, F. Y., \& Mizubuti, I. Y. 2004. Forage evaluation, chemical composition, and in vitro digestibility of continuously grazed star grass. Animal Feed Science and Technology, 113(1), 239-249.

Porto, P. P., Deresz, F., Santos, G. T., Lopes, F. C. F., Cecato, U., \& Cóser, A. C. 2009. Milk production, milk composition, intake and digestibility of tropical forages under intermittent grazing system. Revista Brasileira de Zootecnia, 38(8), 1422-1431.

Rangel, A. H. N., Guedes, P. L. C., Albuquerque, R. P. F., Novais, L. P., \& Lima Júnior, D. M. 2009. Desempenho produtivo leiteiro de vacas Guzerá. Revista Verde de Agroecologia e Desenvolvimento Sustentável, 4(1), 85-89.

Santos, F. A. P., Martinez, J., C., \& Greco, L. F. 2008. Nutrição de vacas em lactação, no período chuvoso, para a produção intensiva de leite em pasto. Caderno Técnico de Veterinária e Zootecnia, 57, 1-39.

Santos, G. T., Kazama, D. C. S., Kazama, R., \& Petit, H. V. 2010. Scientific progress in ruminant production in the 1 st decade of the XXI century. Revista Brasileira de Zootecnia, 39(SUPPL. 1), 478-490.

Silva, J. J., Carvalho, D. M. G., Gomes, R. A. B., \& Rodrigues, A. B. C. 2012. Produção de leite de animais criados em pastos no Brasil. Veterinária e Zootecnia, 17(1), 26-36.
Sniffen, C. J., O'Connor, J. D., Van Soest, P. J., Fox, D. G., \& Russell, J. B. (1992. A net carbohydrate and protein system for evaluating cattle diets: II. Carbohydrate and protein availability. Journal of Animal Science, 70(11), 3562-3577.

Souza, B. M. 2006. Consumo e ambiente ruminal de vacas Holandês-Zebu em lactação sob pastejo de Brachiaria spp suplementadas com diferentes quantidades de concentrado. $\mathrm{PhD}$, Universidade Federal de Minas Gerais, Belo Horizonte, Minas Gerais, Brasil.

Van Soest, P. J., Robertson, J. B., \& Lewis, B. A. 1991. Methods for dietary fiber, neutral detergent fiber, and nonstarch polysaccharides in relation to animal nutrition. Journal of Dairy Science, 74(10), 3583-3597.

Recebido: 20 Agosto 2018

Aprovado:21 Setembro 2018

Publicado: 26 Novembro 2018

Licenciamento: Este artigo é publicado na modalidade Acesso Aberto sob a licença Creative Commons Atribuição 4.0 (CC-BY 4.0), a qual permite uso irrestrito, distribuição, reprodução em qualquer meio, desde que o autor e a fonte sejam devidamente creditado 